DOI: https://doi.org/10.47405/mjssh.v6i4.770

\begin{tabular}{|c|c|}
\hline$x=1+2$ & Malaysian Journal of Social Sciences and Humanities (MJSSH) \\
\hline Malaysian Journal of & Volume 6, Issue 4, April 2021 \\
\hline (MJ-ssH) & e-ISSN : 2504-8562 \\
\hline & $\begin{array}{l}\text { Journal home page: } \\
\text { www.msocialsciences.com }\end{array}$ \\
\hline
\end{tabular}

\title{
Elemen Membuat Rasionalisasi Menggunakan Sumber Sejarah
}

\author{
Siti Kisni Kisson ${ }^{1}$ \\ 1Universiti Malaysia Sabah (UMS) \\ Correspondence: Siti Kisni Kisson (ctniesk@gmail.com)
}

\begin{abstract}
Abstrak
Kajian ini meneroka pembinaan Kemahiran Pemikiran Sejarah (KPS) untuk elemen membuat rasionalisasi dengan menggunakan sumber sejarah. Model pemikiran sejarah yang mengetengahkan proses kontekstualisasi dan pengesahan bukti diintegrasikan dengan sumber sejarah dalam bentuk teks. Tiga sumber sejarah berkaitan dengan tajuk perjuangan Mat Salleh menentang pendudukan British di Sabah pada abad ke-19 telah digunakan. Kajian ini menggunakan pendekatan kualitatif dengan reka bentuk kajian kes kolektif. Empat belas pelajar dari dua buah sekolah menengah kebangsaan harian di Sabah, menjadi sampel kajian. Kaedah pengumpulan data kualitatif adalah melalui kaedah pemerhatian, temu bual kumpulan berfokus dan analisis dokumen. Didapati majoriti daripada 14 pelajar dapat membina elemen membuat rasionalisasi. Elemen membuat rasionalisasi dapat memberikan gambaran perbandingan kehidupan masyarakat dahulu dan masa kini. Dapatan lain menunjukkan para pelajar boleh meneroka persamaan kehidupan masyarakat dahulu dan masa kini; meneroka perbezaan dalam kehidupan masyarakat dahulu dan kini; serta menganalisis punca-punca penentangan Mat Salleh. Dapatan kajian menunjukkan pembelajaran menggunakan sumber sejarah dapat membantu para pelajar membina KPS dengan elemen membuat rasionalisasi.
\end{abstract}

Kata kunci: kemahiran pemikiran sejarah, elemen membuat rasionalisasi, sumber sejarah, kontekstualisasi, pengesahan bukti

\section{Elements of Making Rationalization Using Historical Sources}

\begin{abstract}
This study explores the construction of Historical Thinking Skills (KPS) for the element of making rationalization using historical sources. Models of historical thinking that highlight the process of contextualization and corroboration are integrated with historical sources in the form of texts. Three historical sources related to Mat Salleh's struggle against the British rule in Sabah in late 19th century were used. Qualitative approach were used with the design of a collective case study. Observation, focus group interviews and document analysis were carried out to collect the data needed. Fourteen students from two national secondary schools in Sabah, Malaysia were selected using purposive sampling. It is found that majority students are able to develop Historical Thinking Skills (HTS) with the elements of make rationalizations in the process of contextualizing and corroboration. This study showed that elements of rationalization can provide a comparative picture of society's life then and now. Other findings showed that students can explore the similarities of past and present society; explore the differences in community life then and now; as well as analyzing the causes of Mat Salleh's opposition. Findings also showed that using historical sources in history learning can help students build HTS with the element of rationalization.
\end{abstract}


DOI: https://doi.org/10.47405/mjssh.v6i4.770

Keywords: historical thinking skills, element of rationalization, historical sources, contextualization; corroboration

\section{Pengenalan}

Sistem pendidikan memainkan peranan untuk membentuk warganegara sesebuah negara. Antaranya, penekanan terhadap mata pelajaran Sejarah sebagai pembentuk generasi muda dalam sesebuah masyarakat (Wilschut, 2015). Sejarah turut dilihat sebagai pembentuk masyarakat yang berpengetahuan dan memahami warisan sejarah, serta mempunyai unsur-unsur perpaduan negara (Twells, 2015). Sehubungan itu, penyampaian mata pelajaran Sejarah perlu dirancang agar dapat mencapai matlamat kurikulum, selain membentuk nilai patriotisme dan jati diri dalam kalangan pelajar sesebuah negara (Anuar et al., 2015). Justeru, keupayaan mata pelajaran Sejarah sebagai pembentuk generasi muda yang mencintai negara sering mendapat perhatian dalam sistem pendidikan negara.

Sehubungan itu, perkembangan mata pelajaran Sejarah dalam sistem pendidikan di Malaysia menunjukkan pelbagai usaha dan langkah telah dilaksanakan oleh kerajaan. Misalnya, Sejarah telah dijadikan mata pelajaran teras dalam Kurikulum Standard Sekolah Menengah (KSSM). Seiring dengan perubahan tersebut, berlaku pengubahsuaian dalam objektif mata pelajaran Sejarah. Antaranya, kepentingan merangsang pemikiran pelajar sepanjang proses pengajaran dan pembelajaran (PdP) dilaksanakan. Turut ditekankan ialah kepentingan pemikiran kritis, patriotisme, nasionalisme dan pemikiran sejarah (Kementerian Pendidikan Malaysia, 2014).

Selanjutnya, Kemahiran Pemikiran Sejarah (KPS) turut menjadi teras dalam mata pelajaran Sejarah. Penekanan terhadap penyampaian KPS turut memenuhi keperluan pembelajaran alaf ke-21. Sejajar dengan perkembangan pendidikan pada peringkat global, pembinaan elemen-elemen KPS menjadi teras utama mata pelajaran Sejarah. Kemahiran berfikir menjadi keutamaan berbanding penyampaian kandungan dan fakta sejarah. Para pelajar seharusnya menjadi sejarawan kecil di bilik darjah. Untuk itu, penggunaan sumber sejarah dalam PdP mata pelajaran ini harus diperkenalkan kepada para pelajar. Hal ini adalah sejajar dengan perubahan terhadap sistem pendidikan negara yang berlaku secara dinamik, seiring dengan keperluan semasa.

Hal yang demikian, sebagai seorang pendidik yang telah bertugas lebih daripada 20 tahun, penyelidik terlibat secara langsung dalam perkembangan mata pelajaran Sejarah. Penyampaian Sejarah kepada para pelajar tidak seharusnya terikat dengan fakta dan kandungan buku teks semata-mata. Para pelajar juga tidak seharusnya dibebankan dengan kaedah hafalan dan menjawab peperiksaan semata-mata. Pendekatan, kaedah dan strategi yang sesuai perlu digunakan dalam PdP agar berlaku pembinaan KPS. Dalam kajian ini, penyelidik berusaha untuk meneroka pembinaan elemen membuat rasionalisasi dengan penggunaan sumber sejarah dalam bentuk teks (teks sumber sejarah) dalam pembelajaran Sejarah di sekolah menengah di Sabah.

\section{Sorotan Literatur}

Pelbagai kaedah dan strategi telah digunakan dalam PdP mata pelajaran Sejarah. Namun demikian, sifat sejarah yang memerlukan pentafsiran seharusnya diajar dengan kaedah yang menekankan perbahasan, perbincangan dan latihan mempersoalkan maklumat sejarah (Whitehouse, 2018). Pengetahuan sejarah perlu difahami melebihi paparan fakta dan maklumat dalam buku teks. Para pelajar boleh bertindak aktif dengan menggunakan sumber sejarah sebagai sumber mendapatkan maklumat sejarah (Kisson, 2021). Justeru, penggunaan sumber sejarah memberikan para pelajar peluang untuk berbahas, bersoal-jawab dan memberikan pendapat sejarah mereka. Penggunaan sumber sejarah pada boleh memberikan para pelajar gambaran bahawa sejarah itu dibina daripada pelbagai pendapat sejarawan dengan sokongan bukti. 
Sehubungan itu, penggunaan sumber sejarah dalam PdP merupakan aplikasi tindakan seorang pakar sejarah untuk membuktikan kebenaran sesuatu peristiwa. Realitinya dalam kajian pensejarahan, maklumat sumber sejarah tidak diterima begitu sahaja. Sebaliknya, maklumat yang ditemui harus dinilai, dipersoalkan dan disiasat kebenarannya (Zajda et al., 2017). Proses tersebut memerlukan kemahiran menyiasat, menyoal, menaakul dan mentafsir sesuatu peristiwa atau tokoh sejarah (De la Paz et al., 2016). Setiap maklumat sumber sejarah dibuat perbandingan dengan maklumat daripada sumber sejarah yang lain (Wineburg et al., 2014). Dalam erti kata lain, penggunaan sumber sejarah memberikan peluang kepada para pelajar untuk membuat perbandingan maklumat dengan meneroka, menganalisis dan memberikan tafsiran terhadap fakta sejarah yang ditemui.

Selanjutnya, penggunaan sumber sejarah dalam kalangan pelajar telah menjadi perhatian sejak beberapa lama (Britt et al., 2018; Burton et al., 2015). Kajian sebelumnya mendapati bahawa terdapat perbezaan penggunaan sumber sejarah oleh sejarawan berbanding para pelajar yang dianggap sebagai novis (Neumann, 2015). Pada masa sama, didapati tidak mudah untuk pelajar memahami sumber sejarah memandangkan sumber sejarah jarang ditulis untuk tujuan penyiasatan para pelajar (Braasch et al. 2014). Penggunaan sumber sejarah dalam PdP yang melibatkan pelajar masih berhadapan dengan cabaran. Hal ini ada hubungannya dengan latar belakang para pelajar yang terhad dengan penggunaan buku teks semata-mata (Kucan et al., 2017). Hal ini bermakna, terdapat perbezaan tindakan antara pakar sejarah dengan pelajar dalam penggunaan sumber sejarah. Dengan itu, penggunaan sumber sejarah dalam kalangan pelajar perlu diteroka lebih lanjut bagi mengenal pasti kesesuaian penggunaannya dalam PdP di bilik darjah.

Hal yang demikian, kajian ini meneroka penggunaan teks sumber sejarah dengan mengenal pasti pembinaan elemen membuat rasionalisasi dalam PdP Sejarah di bilik darjah. Model pemikiran sejarah (Wineburg, 2010) yang mengetengahkan proses kontekstualisasi (contextualization) dan pengesahan bukti (corroboration) telah diintegrasikan dengan penggunaan sumber sejarah. Tiga teks sumber sejarah berkaitan dengan perjuangan Mat Salleh menentang pendudukan British di Sabah pada abad ke-19 telah digunakan. Kajian ini melibatkan 14 orang pelajar Tingkatan Empat dari dua buah sekolah menengah di Sabah.

\section{Kemahiran Pemikiran Sejarah}

Kajian terdahulu turut membincangkan keperluan melibatkan pelajar dalam pemikiran sejarah (Seixas, 2017). Dalam kajian ini, konsep pemikiran sejarah adalah merujuk kepada Huraian Sukatan Pelajaran Sejarah Tingkatan Empat (Kementerian Pendidikan Malaysia, 2003, 2018). Membuat rasionalisasi adalah salah satu elemen dalam KPS. Dengan aplikasi KPS, objektif mata pelajaran Sejarah untuk merangsang dan mengembangkan daya pemikiran kritis dan analitis dapat dipupuk. Justeru, kemahiran menganalisis, merumus serta menilai fakta-fakta sejarah Malaysia dan dunia secara rasional dapat ditingkatkan (Kementerian Pendidikan Malaysia, 2015, 2018).Sehubungan itu, elemen membuat rasionalisasi berkaitan dengan tindakan membayangkan diri dalam peristiwa masa lalu, seharusnya dapat merasionalkan kewujudan fakta-fakta sejarah (Talin, 2015). Kemahiran ini turut melibatkan penggunaan akal fikiran dan membuat pertimbangan yang wajar dalam menyelesaikan sesuatu persoalan yang timbul daripada peristiwa sejarah (Kementerian Pendidikan Malaysia, 2015, 2018). Justeru, penggunaan sumber sejarah boleh digunakan sebagai bukti untuk menyokong atau menolak maklumat sejarah yang ditemui. Pembinaan elemen rasionalisasi boleh memberikan peluang kepada para pelajar untuk berfikiran rasional dalam menerima maklumat sejarah.

\section{Model pemikiran sejarah}

Bagi memahami dan meneroka pembinaan elemen membuat rasionalisasi, model pemikiran sejarah (Wineburg, 2010) yang mengetengahkan proses kontekstualisasi (contextualization) dan pengesahan bukti (corroboration) telah integrasikan dengan sumber sejarah. Sumber sejarah telah dibaca, dianalisis dan diberikan tafsiran oleh para pelajar dalam proses kontekstualisasi dan pengesahan bukti.

\section{Kontekstualisasi}


Kontekstualisasi membantu para pelajar mentafsir sumber sejarah dengan memahami masa dan tempat berlakunya peristiwa sejarah tersebut (Kucan et al., 2017). Proses kontekstualisasi turut dikaitkan dengan pemahaman terhadap konteks sosial, ekonomi dan politik (Reisman \& Fogo, 2014). Untuk kajian ini, proses kontekstualisasi melibatkan para pelajar dengan tindakan untuk menganalisis sama ada terdapat peristiwa lain yang berlaku pada masa yang sama dengan peristiwa dalam teks sumber sejarah (Reisman, 2012). Keseluruhannya, proses kontekstualisasi memberikan pemahaman tentang persamaan dan perbezaan kehidupan masa dahulu dan kini dalam konteks sosial, ekonomi serta politik.

\section{Pengesahan Bukti}

Proses pengesahan bukti membenarkan pembaca teks sumber sejarah membuat perbandingan pendapat dan maklumat daripada pelbagai sumber yang ada (Seixas, 2017). Proses pengesahan bukti melibatkan para pelajar dengan proses membanding, mencari persamaan atau percanggahan maklumat sumber rujukan (Levisohn, 2015). Proses ini adalah untuk menentukan kebenaran dan kebolehpercayaan fakta yang ditemui (Lund et al., 2017). Dalam kajian ini, pengesahan bukti melibatkan tindakan menganalisis dan membuat perbandingan maklumat daripada tiga sumber sejarah yang berkaitan dengan perjuangan Mat Salleh di Sabah semasa pendudukan British.

\section{Tujuan dan Objektif Kajian}

Kajian ini bertujuan meneroka pembelajaran mata pelajaran Sejarah menggunakan sumber sejarah dengan mengintegrasikan model pemikiran sejarah (Wineburg, 2010). Objektif kajian ini adalah untuk meneroka pembinaan elemen merasionalisasi dalam proses kontekstualisasi dan pengesahan bukti (Wineburg, 2010) oleh pelajar-pelajar Tingkatan Empat di Sekolah menengah harian di Sabah.

\section{Metod Kajian}

Untuk kajian ini, pendekatan kualitatif yang menekankan konteks sosial bagi membolehkan informan berkongsi pandangan, pengalaman dan pemahaman mereka secara mendalam (Creswell, 2014) dipilih. Untuk kajian ini, penyelidik menekankan penerangan terperinci tentang elemen membuat rasionalisasi dalam pembelajaran Sejarah.

Seterusnya, tumpuan kepada bagaimana informan pelajar-pelajar memahami dan mempelajari Sejarah dengan model pemikiran sejarah daripada perspektif mereka sendiri, membawa kepada penggunaan kajian kes (Yin, 2014). Dalam kajian kes, penerangan yang kaya tentang subjek daripada peserta kajian adalah penting (Merriam, 2015). Kes kajian ini melibatkan 14 orang informan iaitu pelajar yang terlibat dalam sesi PdP Sejarah menggunakan model pemikiran sejarah (Wineburg, 2010). Dalam kajian ini, penyelidik menggunakan kaedah sampel bertujuan. Informan pelajar terdiri daripada 14 pelajar Tingkatan Empat daripada aliran Sains dan Ekonomi.

Selanjutnya, kajian ini melibatkan proses kutipan data yang terperinci dan mendalam daripada sumber pemerhatian, temu bual dan analisis dokumen. Strategi menganalisis data merujuk kepada tiga peringkat: peringkat satu (manual); peringkat dua (koding); dan peringkat tiga (tafsiran data) (Corbin et al., 2014). Penyelidik menjalankan pemerolehan data daripada pemerhatian PdP di bilik darjah. Pemerhatian bilik darjah telah dijalankan sebanyak 6 kali bagi setiap sekolah. Teknik temu bual kumpulan berfokus, secara tidak berstruktur dijalankan sebanyak 2 kali. Akhirnya, analisis dokumen terdiri daripada jurnal pelajar dan hasil kerja bertulis pelajar dijalankan.

\section{Hasil Kajian}

Memberikan gambaran perbandingan kehidupan masyarakat dahulu dan masa kini. Dalam proses kontektualisasi, para pelajar memahami perjuangan Mat Salleh dengan pembacaan, penerokaan dan analisis maklumat teks sumber sejarah. Hampir semua pelajar mengambil kira maklumat yang 
DOI: https://doi.org/10.47405/mjssh.v6i4.770

diperoleh daripada sumber sejarah. Jo, Feb, Kin dan Sewi, menerangkan bahawa mereka boleh membandingkan maklumat yang ada persamaan dan perbezaan. Aziz mengakui memahami perjuangan Mat Salleh kerana "guna bukti-bukti ... ada kontekstualisasi." Pelajar-pelajar lain memberikan pendapat yang sama.

"Saya sukalah konteks, sebab kita boleh tahu antara masa, masa perbezaan antara zaman dulu dengan sekaranglah." (Carol)

"Dengan proses kontekstualisasi saya dapat nampak kata kunci yang penting, persamaan dan perbezaan zaman misalnya." (Feb)

\section{Meneroka persamaan kehidupan masyarakat dahulu dan masa kini}

Sekurang-kurangnya separuh daripada 14 orang pelajar berupaya meneroka persamaan kehidupan masyarakat dahulu dan masa kini. Lebih menarik, terdapat pelajar-pelajar melihat aspek "cukai" (ADK3) yang masih sama pada zaman pendudukan British di Sabah dengan cukai yang ada pada hari ini. Beberapa perkara yang dikatakan masih sama dahulu dan hari ini ialah "cukai, tunjuk perasaan dan ada tentera” (AD-K1). Rad menyatakan bahawa “... kami tahu ada cukai dan rasa tidak puas hati dulu dan sekarang. Sama." Carl melaporkan dalam jurnal pelajar bahawa dalam PdP mereka "mencari ada persamaan cukai dulu dan sekarang."

Separuh daripada pelajar boleh memberikan huraian yang jelas tentang kehidupan masyarakat dahulu dan masa kini. Menurut Feb, “ ... banyak kita sama dulu dan sekarang. Hidup susah”. Feb turut mencatatkan sebab berlakunya penentangan oleh Mat Salleh dan masyarakat hari ini, "pertama, sistem cukai diperkenalkan." Sewi menambah bahawa "tindakan Mat Salleh dalam menentang KBBU adalah hanya untuk mendapatkan hak mereka sebagai rakyat disebabkan pembaharuan sistem yang diperkenalkan. Seperti yang berlaku hari ini." Sewi turut menulis dalam jurnal bahawa terdapat "persamaan; sistem cukai, pemerintahan dan bahasa (Bajau dan Suluk)." Pelajar-pelajar turut menganalisis bahawa "antara persamaan konteks pada masa ini dan pada waktu itu ialah perasaan rakyat yang tidak puas hati terhadap cukai yang dikenakan tinggi" (AD-K4).

\section{Meneroka perbezaan dalam kehidupan masyarakat dahulu dan kini}

Majoriti pelajar boleh meneroka perbezaan dalam kehidupan masyarakat dahulu dan kini. Sid berpendapat "pencarian perbezaan, misalnya sosial. Beza dulu ada kebuluruhan, tiada pendapatan, jenayah berleluasa tetapi bersatu hati." Anna, Carol dan Ven memberikan perbezaan dalam sistem pendidikan, cukai dan keselamatan. Selain itu, turut dianalisis perbezaan antara "sekolah pada waktu itu tidak wujud. Pada waktu itu juga ilmu pengetahuan tidak dititikberatkan berbanding pada waktu kini" (AD-K4). Separuh daripada pelajar-pelajar boleh membezakan kehidupan masyarakat dahulu dan masa kini.

"Salah satu kebaikan, kita dapat tahu apa bahasa sebenar zaman dulu-dulu, berbanding sekarang.” (Ven)

"Ekonomi miskin. Sosial susah. Politik, susah. British yang memerintah. Sekarang aman, merdeka dan moden." (AD-K3)

\section{Menganalisis Punca-punca Penentangan Mat Salleh}

Hampir semua pelajar terlibat dengan tugasan yang memerlukan mereka menganalisis setiap patah perkataan yang dibaca. Menurut Rad, "pada pendapat saya lebih baik menganalisis data kerana kalau kita menggunakan buku teks kita lebih membosankan dan sukar." Pelajar-pelajar lain menyatakan bahawa mereka boleh menganalisis dengan lebih mendalam. Carl mengakui bahawa "... ada empat proses dan strategi untuk menganalisis maklumat daripada sumber." 
Lebih daripada tujuh pelajar boleh menganalisis dan menjelaskan punca-punca Mat Salleh menentang pendudukan British di Sabah. Carol berkata bahawa dia "dapat tahu punca penentangan." Avil menulis, "antara faktor penentangan Mat Salleh terhadap KBBU ialah disebabkan perubahan baharu yang diperkenalkan iaitu cukai tinggi yang mengganggu hal ehwal penduduk serta menggugat kuasa pembesar tempatan." Aziz dan Den turut bersetuju dengan pendapat sama, "Mat Salleh membantah cukai yang dikenakan dan peraturan baharu yang membebankan."

Sebahagian kecil pelajar berpendapat bahawa mempertahankan hak menjadi punca penentangan. Sid mengenal pasti bahawa Mat Salleh merupakan seorang pejuang di Sabah kerana sanggup mempertahankan hak. Jo menggambarkan bahawa "Mat Salleh merupakan tokoh yang ada di Sabah, yang mengusir British kerana sewenang-wenangnya mengambil hak kepunyaannya."

\section{Perbincangan Dapatan Kajian}

Kajian menunjukkan bahawa para pelajar membina KPS dengan elemen membuat rasionalisasi dalam pembelajaran Sejarah menggunakan model pemikiran sejarah (Wineburg, 2010) dengan proses kontekstualisasi dan pengesahan bukti.

Sehubungan itu, proses kontekstualisasi menyediakan peluang kepada para pelajar menggambarkan persamaan dan perbezaan kehidupan masyarakat dahulu dan masa kini. Pelajar-pelajar boleh meneroka dan menganalisis aspek-aspek pentadbiran, ekonomi dan sosial masyarakat dahulu. Perbandingan kehidupan dengan masyarakat masa kini lebih mudah, memandangkan hal ini melibatkan gambaran kehidupan sebenar para pelajar. Pelajar-pelajar berupaya merasionalkan persamaan kehidupan masyarakat dahulu dan masa kini. Antara aspek-aspek kehidupan yang dilihat sebagai persamaan ialah cukai dan rasa tidak puas hati rakyat. Mereka turut mengklasifikasikan bahawa sistem pemerintahan, sistem cukai, budaya, suku kaum dan bangsa sebagai persamaan yang wujud antara masyarakat dahulu dan masa kini.

Selanjutnya, dalam meneroka perbezaan kehidupan masyarakat dahulu dan masa kini, dikategorikan aspek politik, sosial dan ekonomi. Didapati pelajar-pelajar boleh memperincikan kehidupan masyarakat dahulu dengan pelbagai kekurangan dan kelemahan. Dalam hal ini, didapati proses pembelajaran Sejarah tidak terbatas kepada fakta masa lalu sahaja. Sebaliknya mereka berjaya menghubungkaitkan masa lalu dengan kehidupan masa kini. Penguasaan KPS membolehkan mereka menghubungkaitkan, menjelaskan serta meramal keadaan masa kini dan masa depan. Dapatan ini menyokong kajian Van Straaten et al. (2016), Van Straaten et al. (2018) dan Körber (2019) yang menekankan kepentingan mempelajari sejarah sebagai masa lalu yang berkaitan dengan kehidupan hari ini dan akan datang. Dapatan ini juga selari dengan kajian Miki et al. (2015) yang menyatakan bahawa keupayaan mengekalkan pemikiran sejarah membolehkan pelajar-pelajar memahami keadaan semasa sebagai hasil peristiwa yang telah berlaku dalam sejarah.

Seterusnya, proses pengesahan bukti membolehkan pelajar-pelajar mengenal pasti faktor-faktor yang menjadi punca penentangan Mat Salleh terhadap British. Pelajar-pelajar secara kendiri menentukan maklumat yang diteroka dalam pembelajaran Sejarah mereka. Pelajar-pelajar dapat membina KPS dengan merasionalkan fakta dan maklumat berkaitan punca perjuangan Mat Salleh. Dapatan kajian ini menyokong cadangan Rantala et al. (2015) agar PdP Sejarah di bilik darjah seharusnya menyampaikan kemahiran berfikir sebagai strategi mengetahui kandungan sejarah dan bukannya dengan cara sebaliknya.

Dapatan kajian turut menunjukkan bahawa proses pengesahan bukti membolehkan pelajar-pelajar meneroka maklumat sekurang-kurangnya dua daripada tiga teks sumber sejarah. Dapatan kajian ini menyamai dapatan kajian Levisohn (2017) yang menunjukkan para pelajar terlibat dengan proses membandingkan maklumat, mencari persamaan atau percanggahan maklumat antara sumber sejarah. 


\section{Kesimpulan}

Melalui sesi pembelajaran yang berulang-ulang, para pelajar memperoleh ilmu pengetahuan secara aktif dan membolehkan mereka membina elemen merasionalisasikan. Pembinaan elemen ini menunjukkan kesesuaian penggunaan sumber sejarah dengan integrasi model pemikiran sejarah (Wineburg, 2010) yang mengetengahkan proses kontekstualisasi dan pengesahan bukti. Penggunaan sumber sejarah turut memperkenalkan kepada para pelajar tentang sifat sebenar Sejarah. Kurikulum mata pelajaran Sejarah boleh berkembang dan lebih dinamik kerana perkembangan dan kepelbagaian pendapat tentang peristiwa sejarah, seseorang tokoh, dan sesebuah masyarakat.

Oleh yang demikian, kajian ini mendapati pembelajaran Sejarah menggunakan sumber sejarah dapat membantu para pelajar membina pemikiran bersejarah. Konsep KPS dapat merangsang pemikiran pelajar melalui aktiviti pembelajaran aktif yang melibatkan proses membuat rasionalisasi. Penggunaan sumber sejarah dalam PdP mata pelajaran sejarah dapat merangsang pemikiran bersejarah para pelajar dan sesuai digunakan sebagai sumber mendapatkan maklumat dalam PdP mata pelajaran Sejarah.

\section{Rujukan}

Anuar Ahmad, Peter, \& Nur Atiqah Tang Abdullah. (2015). Pengetahuan Nilai Patriotisme Pelajar Berdasarkan Pembelajaran Subjek Sejarah. Malaysian Journal of Youth Studies, 13, 95-116.

Braasch, J. L., Bråten, I., Strømsø, H. I., and Anmarkrud, Ø. (2014). Incremental theories of intelligence predict multiple document comprehension. Learning and Individual Differences, 31, $11-20$.

Britt, M. A., Rouet, J. F., \& Durik, A. (2018). Literacy beyond text comprehension: A Theory of purposeful reading. Routledge.

Burton, E. P., Pellegrino, A., and Gallagher, M. (2015). Humanizing the disciplines: Historical thinking and students' understanding of the nature of science. The Georgia Social Studies Journal, 5 (1), 54-67.

Corbin, J., Strauss, A., \& Strauss, A. L. (2014). Basics of Qualitative Research. Sage Publications.

Creswell, J. W. (2014). A concise introduction to mixed methods research. Sage Publications.

De La Paz, S., Monte-Sano, C., Felton, M., Jackson, C., Piantedosi, K.W., \& Croninger, R.A. (2016). 'A historical writing apprenticeship for adolescents: Integrating disciplinary learning with cognitive strategies'. Reading Research Quarterly, 1-22.

Kementerian Pendidikan Malaysia. (2003). Sukatan pelajaran KBSM sejarah (semakan). Kuala Lumpur :Dewan Bahasa dan Pustaka.

Kementerian Pendidikan Malaysia. (2015). Dokumen standard kurikulum dan pentaksiran mata pelajaran sejarah tingkatan satu. Putrajaya: Bahagian Pembangunan Kurikulum.

Kementerian Pendidikan Malaysia. (2018). Kurikulum standard sekolah menengah sejarah, dokumen standard kurikulum dan pentaksiran tingkatan 4 dan 5. Putrajaya: Bahagian Pembangunan Kurikulum.

Kisson, S. K. (2021). Sumber Sejarah pencetus pemikiran bersejarah. Kota Kinabalu: Universiti Malaysia Sabah.

Körber, A. (2019). Extending historical consciousness: Past futures and future pasts. Historical Encounters, 6(1), 29-39.

Kucan, L., Cho, B. Y., \& Han, H. (2017). Introducing the historical thinking practice of contextualizing to middle school students. The Social Studies, 108(5), 210-218.

Levisohn, J. A. (2015). Historical thinking - and its alleged unnaturalness. Educational Philosophy and Theory, 1-13.

Levisohn, J. A. (2017). Historical thinking--and its Alleged Unnaturalness. Educational Philosophy and Theory. 49(6), 618-630.

Lund, E. S., Bråten, I., Eva, W., Brante, E. W., \& Strømsø, H. I. (2017). Memory for textual conflicts predicts sourcing when adolescents read multiple eExpository texts. Reading Psychology, 1-21.

Merriam, S. B. (2015). Qualitative research: Designing, implementing, and publishing a study. In P. A. Hershey. Handbook of research on scholarly publishing and research methods (pp. 125-140). IGI Global. 
Mertens, D.M. (2005). Research and evaluation in education and psychology. Sage Publications.

Miki, Y., Kojiri, T., \& Seta, K. (2015). "If Thinking" support system for training historical thinking. Procedia Computer Science, 60, 1542 - 1551.

Neumann, F. (2015). How does a historian read a scholarly text and how do students learn to do the same? In D. Ludvigsson \& A. Booth (Eds.), Enriching history teaching and learning, challenges, possibilities, practice (pp. 51-66). Linköping University.

Rantala, J., \& van den Berg, M. (2015). Finnish high school students' and university students'ability to handle multiple source documents in History. Historical Encounters, 2(1), 70-88.

Reisman, A. (2012). 'Reading like a historian: A document-based history curriculum intervention in urban high schools'. Cognition and Instruction, 30(1), 86-112.

Reisman, A., \& Fogo, B. (2014). Teaching disciplinary history in secondary history classes. In M. Hougen (Ed.), The Fundamentals of literacy assessment and instruction (pp. 6-12). Brookes Publishing Co.

Seixas, P. (2017). A model of historical thinking. Educational Philosophy and Theory, 49(6), 593-605.

Talin, R. (2015). Historical thinking skills-The forgotten skills? International Journal of Learning and Teaching, 7 (1), 15-23.

Twells, A. (2015). 'More than gaining a mark': Students as partners and co-producers in public history and community engagement. In D. Ludvigsson \& A. Booth (Eds.), Enriching history teaching and learning, challenges, possibilities, practice (pp. 51-66). Linköping University.

Van Boxtel, C., \& Van Drie, J. (2012). "That's in the time of the Romans!" Knowledge and strategies students use to contextualize historical images and documents. Cognition and Instruction, 30 (2), 113-145.

Van Straaten, D., Wilschut, A., and Oostdam, R. (2016). Making history relevant to students by connecting past, present and future: A framework for research. Journal of Curriculum Studies, $1-24$.

Van Straaten, D., Wilschut, A., \& Oostdam, R. (2018). Exploring pedagogical approaches for connecting the past, the present and the future in history teaching. Historical Encounters, 5(1), 46-67.

Whitehouse, J. A. (2018). Critical analysis of Ssources in history: Developing historical thinking. Education and Society, 36(2), 5-14.

Wineburg, S. (2010). Thinking like a historian. Teaching with Primary Sources Quarterly, 3(1), 2-5.

Wineburg, S, Martin, D., \& Monte-Sano, C. (2014). Reading like a historian. Teachers College Press.

Yin, R. L. (2014). Case study research: Design and methods ( $5^{\text {th }}$ edition). Sage.

Zajda, J., Henderson, D., \& Whitehouse, J. (2017). The portrayal of John Curtin as Australia's wartime labor [JW2] prime minister. In J. Zajda, T. Tsyrlina-Spady., \& M. Lovorn (Eds.), Globalisation and historiography of national leaders : Symbolic representations in school textbooks. Springer. 